archives-ouvertes

\title{
Of Open bodies: Challenges and Perspectives of an Open Design Paradigm
}

\author{
Emeline Brulé, Frédéric Valentin
}

\section{To cite this version:}

Emeline Brulé, Frédéric Valentin. Of Open bodies: Challenges and Perspectives of an Open Design Paradigm. 50th Anniversary Design Research Society Conference, Jun 2016, Brighton, United Kingdom. hal-01304721

\section{HAL Id: hal-01304721 \\ https://hal.archives-ouvertes.fr/hal-01304721}

Submitted on 20 Apr 2016

HAL is a multi-disciplinary open access archive for the deposit and dissemination of scientific research documents, whether they are published or not. The documents may come from teaching and research institutions in France or abroad, or from public or private research centers.
L'archive ouverte pluridisciplinaire HAL, est destinée au dépôt et à la diffusion de documents scientifiques de niveau recherche, publiés ou non, émanant des établissements d'enseignement et de recherche français ou étrangers, des laboratoires publics ou privés.

\section{(1) $\$(0)$}

Distributed under a Creative Commons Attribution - NonCommercial - ShareAlikel 4.0 


\title{
Of Open bodies: Challenges and Perspectives of an Open Design Paradigm.
}

Émeline Bruléa*, Frédéric Valentin ${ }^{a}$

${ }^{a}$ Télécom-ParisTech.

*Corresponding author e-mail: emeline.brule@telecom-paristech.fr

\begin{abstract}
Several design practitioners claim to follow an open design philosophy, using open sourcing material, models or tools. But there has been little work on framing the properties of artifacts produced that way, nor on studying how "openness" influence design processes (Aitamurto, Holland \& Hussain, 2015).

In this paper, we propose to investigate Open Design through examples of prosthetic hands. These highly specific and personalized devices have to answer highly sensitive social, personal, subjective and functional requirements. They perfectly illustrate the challenges the Open Paradigm may help tackling, such as greater inclusivity through the reduction of stigma, access to social participation and empowerment of users in general.

First, we build upon the related work to identify properties of openness. We then present the methodology used to review nine different prosthetic hands. Building upon these examples, we frame a critical perspective on openness and how this paradigm encompasses or informs other design practices. We conclude by presenting our current and future work, to provide perspectives on the applications of our essay.
\end{abstract}

Keywords: Open; Prosthesis; Inclusive Design

\section{Introduction}

The "Open paradigm" has been identified in several fields, from Software to Innovation Studies (Aitamurto, Holland \& Hussain, 2015). The open data 
and open research philosophies have gradually come to question all research disciplines and their publication practices. Moreover, open design has been gradually discussed in design research (Aitamurto et al., 2015; Thackara, 2011; Van Der beek, 2012).

Historically, the open paradigm seems to be rooted in three different movements: the needs for industrial standards at the beginning of the XXth century, the ideal of an Open Society, theorized by Popper in the verge of World War II and the Open Source Software movement, born in the eighties (Goëta, 2015). The open paradigm' emergence is linked to two different but intertwined issues: the interoperability of telecommunication systems, and the utopia of a perfect democratic society through the access to knowledge.

The Open Knowledge Foundation has defined openness as a paradigm enabling access and availability, re-use and redistribution, as well as universal participation (Open Knowledge, 2015). In design, Aitamurto et al. (2015) have recently articulated open design practices as deployed during needs finding, ideation, creation and fabrication, as well as during the distribution and circulation of designs. Their definition covers open hardware projects, participatory design practices, as well as highly personalizable, if not self-produced, artifacts. Nevertheless, the effects of open processes on the artifacts thus produced have not yet been widely studied.

Our paper proposes to investigate openness' properties through nine examples of prosthetics. Building upon our review of literature, we outline openness (1) as the inclusion of people and their values during the project framing and ideation process; (2) as space left to users in the formalization process (choice of functions, interactions, aesthetics...); openness may be limited by (3) the level of technical knowledge required to understand and modify a product or (4) the difficulty of access to the fabrication equipment; and may allow (5) a high level of variability and originality of the resultant artifact.

We therefore propose a model to discuss the openness of a production, as a critically addressable characteristics of an artifact. 


\section{Review of Literature}

\subsection{The open paradigm in History, Arts and Design.}

As stated in our introduction, the "open paradigm" emergence seems to be linked to two different, but intertwined issues (Goeta, 2015): the interoperability of telecommunication systems, openness being a necessary value for some innovations (Cruickshank, 2014), and the wish to create an equal and democratic society by granting full access to knowledge.

Several researchers outlined openness as a democratic process. For example, Aitamurto et al. (2015) have recently articulated open design practices as "deployed in the following stages: 1) listening in, 2) interacting and creating with co-designers and the crowd, and 3) sharing with other co-designers and the crowd." In other words, open design practices concern needs finding, ideation, formalization and fabrication, as well as the distribution and circulation of designs. It echoes Van der Beek's reading of Blauvelt (Van der Beek, 2012), who highlights how design has been shifting from delivering a product to setting the conditions for its design. The interest of numerous researchers for Do-It-Yourself practices in the design of technologies (Hurst and Tobias, 2011) or community-based participatory design are good examples of this paradigm shift. They have proved to be empowering for a large variety of publics (Druin, 2002; Halskov \& Hansen, 2015), although their limits are worth considering. For example, Kensing and Blomberg (1998) as well as Bowen (2010), show that participation in the design process might be limited by social issues surrounding a project (see also Cruickshank, 2014, p.44), by the methods used or by the required knowledge to collaborate freely.

Open design is initially the application of open source principles to design, as stated by Ronen Kadushin in his Open Design manifesto (2010). Following this conception, the designer provides digital blueprints of her designs, allowing them to be used (produced), modified and shared. However, recent descriptions of open design seem to be more interested in the implications for design practice of a shared design process 
(Aitamurto et al., 2015; Van Der beek, 2012). Even If open design can be linked in many ways to the development of IT and personal CNC (Atkinson, 2011), it is to be acknowledged that there have been numerous design projects before the birth of said digital fabrication techniques (Cruickshank, 2014, p.4). For example, Enzo Mari's Autoprogettazione (1974) aimed at allowing anyone to build basic furniture, using wood and nails. Mari distributed his blueprints as free leaflets, encouraging people to start their own production and to modify his models.

Open source projects (on both hardware and software levels) also make a claim at democracy and interoperability, which have an impact on the distribution and circulation of resultant products. (We acknowledge the philosophical differences between open source and free software. However, as this is not the focus of this paper, we will not expand on this matter.) Open source projects encourage people to drive it further, to tinker and to get implicated (see for example the Open Source Initiative: http://opensource.org/history), either by documenting or technically contributing. But they also present issues: the knowledge required to make changes may be high, the community may not be as welcoming as claimed (Toupin, 2014) or the necessary equipment may not be accessible to all.

There have also been researches on openness in artifacts and products. Umberto Eco (1962) focuses on works of art and artistic practices to define "an open work". For Eco, it relies on the spectator interpretation, generating more information than is originally contained in the piece, by allowing various interpretations depending on the public, the situation, etc. Thus, if every work of art is in some respect "open," some are designed in certain ways that they encourage interpretation, either mechanically (what Eco refers to as "work in movement") or conceptually, thus being intentionally more open. If Eco does not directly cite objects from the realm of design (although he does mention the case of organisable bookshelves), we argue that it describes quite well ludic design artifacts (Gaver et al., 2004; Mivielle \& Gentès, 2012). As stated by Gaver, ludic design should avoid "clear narrative of use" and stay "open- 
ended" (Gaver et al., 2004), i.e. enabling the user's participation through artifact's interpretation and actuation. Mass customization (as first defined by Joseph B. Pine (1993)) also relates to Eco's work, as it seeks to allow variations in the production of artifacts through shared tool kits and flexible designs that can be reconfigured (Salvador, De Holan \& Piller, 2009).

\subsection{Design and prostheses}

Even though prostheses (such as prosthetic hands) are designed to meet a specific and narrow range of cases, they are to address different bodies, and need to be fitted to each individual. Prosthetics have never been mass-produced, but they are no longer fabricated individually either. They are "fitted" by medical professionals: most are generic models with few customizable components (see examples 1, 2 and 3). But body variability may be addressed from three perspectives: (1) a "one size fits all" philosophy, i.e. products aiming at universality (Salvador, et al., 2009); (2) the addition of variables in design, much like accessibility features; (3) inclusive design, which aim to design for a very low number of users with highly specific needs.

If there have been decorated prosthetics in the past (see for example this Victorian-era prosthetic arm showing fine decorated metal work at the Museum of Science, London: http://tinyurl.com/jfxgseh), human-like models are often preferred for social acceptability (Pillet $\&$ DidierjeanPillet, 2001). Nevertheless, it is to be acknowledged that there are few studies on the aesthetic aspect of prosthetics (Sansoni, Wodehouse \& McFadyen, 2015). Radical aesthetic propositions are quite recent, as the interest of fashion for prosthetics increased: from Alexander McQueen's creation for Aimee Mullins to the Alternative Limb Projects, prosthetics may now come in a large variety of forms. We observe shift in prosthetics recognition, from the mere replacement of a limb, aesthetically and practically bound to mimic human organs, to creative exploration by figures such as Aimee Mullins. The fact she proudly wears non-mimetic prostheses, either in mainstream media or in artistic collaborations proposes to invert the stigma (see for example Cremaster cycle 3 (2002) 
by Matthew Barney, where she act wearing prothetic cheetah legs or acrylic transparent legs (http://tinyurl.com/gowgj4u)). We argue that this desacralization, or "profanation" (Agamben, 2009), of human form through the redefinition of bodies by creative prosthesis permitted to allow for new creative approaches to the design of prostheses. It has more generally been pointed out in every area where design meets disability (Pullin, 2009), and question the ways body and embodiment are taken into account in the design process.

\section{Methodology}

Our analysis methodology was inspired by McClung Fleming (1974)'s framework, eg. (1) identification through the description of the history, material, construction, design and function of an artifact, (2) evaluation in regards to similar objects, (3) cultural analysis to elicit its social and cultural conditions of existence and (4) the interpretation of the values thus conveyed.

In section 2, we articulated how various design approaches were aiming at, or claiming for, openness. We underlined various open processes, either during needs finding, ideation, creation and fabrication, distribution and circulation of designs and properties of the artifacts themselves, who may or may not allow original customization. We also highlighted that participation in the design process might be limited by larger social issues, by the methods used or the required knowledge to collaborate freely.

We thus outline openness (1) as the inclusion of people and their values during the project framing and ideation process; (2) as space left to users in the formalization process (choice of functions, interactions, aesthetics...); openness may be limited by (3) the level of technical knowledge required to understand and modify a product or (4) the difficulty of access to the fabrication equipment; and may allow (5) a high level of variability and originality of the artifact.

We chose to work on prostheses because they have always required variability and adaptability. Little discussed in design research as they 
belong to the medical realm, we saw these examples as the occasion to understand how performative (Van Der Beek, 2012) design can be.

These dimensions allow for a contrastive analysis of our examples (considered in terms of material, cultural and semiotic attributes). We first present the four common types of prosthetics hands: myoelectrical, mechanical, passive, and functional. We then analyse personalized or open source counterparts.

\section{Examples of Prosthetic Hands.}

\section{Example 1: Passive cosmetic hand, by Steeper.}

Steeper's passive cosmetic hands are realistic prostheses filled with foam and covered with a PVC or silicone glove that gives the hand details (http://tinyurl.com/zgdrvjh). They are presented as lightweight and cost effective, adaptable to various studs. They exist in a finite number of shape and size (five for adults, and five for children), as well as in 19 colours, which means that their fabrication can be automatized. They provide a minimum functionality (pushing, pulling) but mainly aim at reducing social stigma and restore body image by being lifelike.

The company does not precise whether or not they included users in the design. Quite probably, it was mostly developed by prosthetists. They may be personalizable to some extent (through painting, for example), but this is not the aim of the product. Their degree of originality (in comparison to bodies without prosthetics) is low.

\section{Example 2: Functional hands, by Texas assistive devices}

Texas assistive devices proposes prosthetic devices for people living with hand dysfunction or amputation. It is composed of a metallic terminal device, called the $\mathrm{N}$-Abler, that comes in a variety of types depending on the type of impairment (hand or arm amputation, etc.). The $\mathrm{N}$-Ablers are compatible with a large serie of functional tools, from hooks to gardening, cooking, tinkering, eating or hygiene utensils. These tools may be changed accordingly to the activity the user is engaged in, and cover most of 
everyday tasks and activities, although the user would need to acquire numerous (and quite expensive) extensions. Texas Assistive Devices describe the $\mathrm{N}$-Abler as a "self-esteem builder," (http://tinyurl.com/gks3eaz) although its social acceptability might be low (Fishman \& Kay, 1964; Pillet Didierjean-Pillet, 2001). The website mostly aims at professional prosthetists, through technical precisions and a loaner offer so they can test it with their patients.

The company does not precise whether or not they included users in the design. This type of prosthesis is personalizable, within a given set of possibilities. One could easily hack an everyday object to add a tool to the collection. Aesthetically, it is quite far from a body, but its aesthetic is purely practical / functional. Thus, it has a limited originality.

\section{Example 3: Mechanical hand, by Steeper}

Steeper's mechanical hand exhibits three fingers (http://tinyurl.com/j23vvg7). When flexing the wrist, the hand is able to grasp an object: the hands are operated using cables and springs, either to open or to close the hand. The hands have a very functional aesthetic: the bare metal make them seem robust, all the mechanisms are visible etc. They are presented as lightweight compared to previous models, come in four sizes (from child to adult), and may be covered by "cosmetic gloves," i.e. silicone or PVC human like gloves that can be fitted on it, which come in 19 different colors (see example 1). They can be adapted to various wrist systems.

Again, it does not seem that users have been involved in the design. The structure of the hand itself is hardy personalizable by the user, only the cosmetic glove might be adapted. Furthermore, these gloves exist in four sizes only (there were 10 for cosmetic gloves, by the same company), and the grasping system in prosthetic hands is nothing new. Therefore, the level or originality may be considered as low. 


\section{Example 4: Be Bionic, by Steeper}

The BeBionic hand, by Steeper, is an articulated electronic device mimicking the structure of the human hand (http://tinyurl.com/jzbewgv). It has a clean, streamlined, science-fiction like aesthetic and is available in two colors (black or white). It is designed to handle everyday activities through 14 different patterns: finger pointing, different kind of grasps etc. The hand's motors react to muscle contraction signals. Its patterns are adaptable by a medical professional using a custom software. If it can be fitted to different types of wrists or wrist mechanisms, it only exists in two sizes: small and medium. It is sold for $\$ 11000$. That project focuses on efficiency but could not exist without an advanced technical and medical infrastructure.

Again, Steeper says nothing about having involved users in the process, although they testify of their use. It is hardly customizable because of its highly technical nature, although the proposed hand gestures can be finetuned. The user guide actually states that users should not try to modify their hand in any way. It is very close from the structure of a human hand, while its streamlined aesthetic embodies positive representations of the future. It thus feels familiar and has a low degree of originality.

\section{Example 5: Feather Armour, by Alternative Limb Project}

Feather Armour is a functional customized prosthetic arm, designed by Sophie de Oliveira Barata and Rowena Vickerman for actor Grace Mandeville, as part of the Altenative Limb Project (http://tinyurl.com/gwcl5pu). Built with metal, feathers, beads, silicone and acrylic resin around a hook, it is designed much like a fashion accessory. Its aesthetic radically differs either from functional or cosmetic prosthesis, but remains comfy and functional as it is designed with respect for the prosthetic medical requirements, fitted by a professional. Its owner explains that she has "worn prosthetic arms that look real and they just get in the way. They look normal, but [she doesn't] really want to look normal." (Saner, 2014) Such Alternative Limbs are made to measure, with cost starting at $1000 \mathrm{f}$ (and up). Thus, they are definitely not accessible to 
all. But their design process highly involves the wearer and the resultant artifact has a high originality level, overturning the stigma through aesthetics.

The ideation process did involve the end user a lot, as it was completely custom made. The formalization process may have involved her as well, but mostly for feedback. Modifying it would require crafting skills and highend materials. If the hand's function (the hook) is a pretty common type of prosthesis, its visual design does not look like any other.

\section{Example 6: Bam Bam Prosthetics}

Bam Bam Prosthetics were developed by Nick Richardson during his master thesis at the Maryland Institute College of Art. They are composed of a soft socket made of canvas and a multi-functional terminal device in bamboo, which can be completed by various tools (such as a rake or a hammer (http://tinyurl.com/hs77wvj). Richardson explains that (http://tinyurl.com/ngmkob5) he first used the tools he knew and were widely available around him (plastic, etc.), but quickly realized those means of fabrication would not be available anywhere. As Bam Bam prosthetics were destined to people living in developing countries (where $80 \%$ of the world's amputees live), they can be manufactured locally, with cheap and widely available materials. At the contrary of traditional prosthetics, the soft socket allows it to be fitted without the help of a specialist. The focus of the design is to meet the needs for functional, durable and low-cost prosthetics and to allow amputees to get back to the workforce in countries mostly relying on farming as a mean of living. The project was exhibited in the Cooper Hewitt Museum, as part of the Beautiful Users exhibition.

Although this is a self-initiated project, it seems that Richardson tried to include actual users in the design process. The technical skills and equipment required are widely shared. If there has been researches on the use of bamboo for prostheses (Banerji \& Banerji, 1984), and if such use can be traced back to wood legs, the design of the soft pocket and of the arm's end are new propositions, to our knowledge. 


\section{Example 7: Raptor Reloaded, by Enabling the Future.}

Enabling the Future (http://enablingthefuture.org/) is a global network of volunteers that participates in the conception, production and distribution of various open sourced upper prosthetic limbs. They operate mostly in "underserved communities", providing their prosthesis to children and to people that can't afford the industrial models. Most of the prostheses proposed are mechanically operated, with the exception of a recent myoelectric model. All the prosthetic hands are designed to be 3D printed, but the volunteer based production principle means that different models of 3D printers and different types of materials can be used, producing different results. The overall aspect of the object does not try to be realistic. The web site states clearly that they do not intend to compete with professionally made prostheses and see their models as "tools" to provide more practicality and deepen social acceptability.

The ideation process is shared amongst the community but does not require the user's participation directly. Monthly "design challenges" now encourage the community to design new devices, inspired by the current designs. The formalization process seems to sometimes involve the user as they are associated during the fabrication and the fitting of the object. Otherwise, it does not seem like the design are highly customizable, except in the use of various colors for some of the children's prosthesis. As the initiative does not only provide the design, but also the technical means, the users only need to know how to operate (and sometimes repair) the prosthetic hand. However, repairing the prosthesis might require an access to a 3D printer. In terms of originality, the design displays a rather mechanical aesthetic and does not try to hide its origins: it is different from common prosthesis and its basic materials and mechanism encourage modifications (see the Raptor Reloaded on the website page: http://tinyurl.com/hsvjvd2).

\section{Example 8: Bionico.}

Bionico is an open source project of myoelectric arm, initiated in 2012 by Nicolas Huchet when he discovered fab-labs. Still in prototype phase, it 
aims at allowing amateurs to build bionic prostheses using affordable material, such as Arduino and 3D printing pieces. A Bionico costs around $200 €$, far from commercialized models. Despite that, Bionico does not try to compare with high-end models, knowing they involve a great deal of currently unreachable technological advances. Rather, the focus of the group is to gather a community in order to make a myoelectric arm as inexpensive as possible. As expressed by Nicolas Huchet (https://bionico.org/about/), the political and social engagement (sharing knowledge, gathering a community for a more equalitarian world) is the main aim of the project. Currently, the prosthesis remains overall very unpractical, and serves mostly as a proof of concept, but also as an embodiment of the project during public events (where Huchet wears the hand, having himself lost his hand in a work accident). In this regard, the aspect of the hand seems rather efficient: it does look like a prototype, which reflects its $D / Y$ roots and makes it familiar to the makers community (http://tinyurl.com/zyce7qv).

So we can consider the ideation and formalization process as open, as they involved the community and impaired users. However, various technical skills are required to build it. The same goes for the equipment (3D printers, servomotors, etc.). The design does not try to differ from existing models, but does so in terms of conception - which is reflected in its aspect.

\section{Example 9: Iko}

Iko creative prosthesis is the result of Carlos Arturo Torres' internship at Lego Future Lab. It won Core77's design award for best "open design". The prosthesis designed for children allows the user to snap Lego pieces around it and to operate them through its built-in rotative motor. The device was designed to be compatible with any Lego branded set, particularly the Lego "systems" more focused on the construction of mechanism: the material is thus broadly accessible, with a wide range of choices. The designer also designed a little backhoe model as a starter set for the prosthesis. Torres' focus in this design is its social catalysing aspect built around the playfulness of Lego, as demonstrated in the designer's 
discourse focalizing on its empowering creative and collaborative dimensions. We can observe Torres' precise attention to Lego's technical status: "I designed a backhoe LEGO set difficult enough to build where the kid used the people around as co-players"(http://tinyurl.com/oohp82I). The designer tuned the Lego model in certain ways to encourage a given behavior, requiring both a fine understanding of the users' capacity in terms of knowledge requirements and access to resources. The openness of the project revolves around Lego's low knowledge requirement and the proximity of parents and potential playmates to fill the difficulty gap intentionally set in the model. The user' learning process is therefore eased, allowing her to quickly discover the basics required to build her own design, while involved from the beginning in the ideation and formalization process.

Parts of the ideation and formalization process is determined by the designer that defines the properties and boundaries of another creative space in which the user is welcome to express his own forms and ideas. The use of Lego bricks ensures the access, and eases the progression towards the required knowledge through the use of an accessible, easy to understand material. While using similar principles as other myoelectric prosthesis (a rotor embedded in the arm), the object gathers the attention out of Lego's playfulness.

\section{Discussion}

As Umberto Eco says about works of art, we argue that every artifact is open to some degree. However, some artifacts are designed in such ways that they expand the design space, thus being more open. Therefore, openness is not a binary value (open/closed) but rather something that can be expressed in many ways (affecting different stages of the design process and production) and to various degrees.

If we look at those examples from a broader perspective, we can highlight two different design approaches. In some cases, the structure is made to accommodate a few options or variables, but is quite constrained in the 
possibilities (cases 5, 7 and 8 ). In others, the design project relies on every single user's design skills (cases 6 and 9).

A project's openness is relative to its context. The open paradigm is not about enforcing the design and use of universal products, or even of universal structures to be adapted, but rather proposes artifacts relevant and adaptable to certain settings. Let's take, for example, the differences between BamBam Prosthetics (case 6) and the Raptor Reloaded Hand (case 7). Even with a substantial number of volunteers ready to devote their 3D printers, time and knowledge, Enabling the Future's production is not available to anyone anywhere. Moreover, the Raptor Reloaded still necessitates a fitting and assists a rather limited number of activities. On the other hand, Bambam Prosthetics requires widely available materials and tools and seems to open wider possibilities for customization, but rely entirely on users' or users' relations' practical skills.

If the latter approach requires a deeper engagement from people, it also may allow them to reach a greater level of agency. Let's use Iko the Lego hand as an example: it accommodates one's values, and adapts to selfpresentation and agency. Although it is not open source, Iko encourages modifications by its structure itself. It brings a mass produced product (Lego), its easiness of assemblage and its ludic properties towards an inclusive use. The user becomes a "practitioner" of the artifact and of herself.

Thus, openness is a property of an artifact (or rather, of an apparatus) allowing a certain degree of involvement by the user. This property can manifest itself in various manners, in regards to the context and intentions.

These two approaches to openness, either as the production of a universal artifact or as the involvement of the user's design skills, questions the relations of power between design production and users. There is to be a balance between the effort and responsibility gained by users and the seamlessness of an open production. It does, of course, have political and ethical implications. Relying on the user's / practitioner's skills should not make her bear alone the responsibility of her inclusion in society, but 
rather to support her in making choices on her own. It should not be reserved to people who cannot afford a more efficient or adequate prosthesis-for example Bionico's designer does not wear it, but has access to a high-end prosthetic hand. It is to question industrial production and to open new ways of making and doing. Our five last examples all push further the possible aesthetic of bodies in contemporary times, much like more traditional prostheses did in their time (Pillet \& Didierjean-Pillet, 2001). They invert the social stigma, and affirm other kinds of subjectivities, even though they may not be the strongest or most practical.

What our analysis shows, is that the open paradigm expands the design space, questions and renews what a prosthetic hand can be, but also how and by whom it can be done and the conditions of its productions. We argue that openness might be an aesthetic paradigm: through her production, the designer organizes agents and elements to define the specific conditions of existence of a design space, in which the user is invited to participate.

Openness can be considered as an aesthetic in the deleuzian sense of the term: an encounter with an object / project that induces a rupture, that proposes new ways of being, living and acting in the world.

As stated by O'Sullivan (2010) reading Deleuze and Guattari:

"At stake then are two moments in what I am calling the aesthetics of contemporary art: one of dissent (a turn from, or refusal of, the typical) and one of affirmation (of something different). Two operations then: one of criticism, one of creativity. We might call the first parasitical (on an already existing body, for example an institution); the second, germinal (the birth of the new)."

Thus the open paradigm applied to prostheses de-constructs, breaks something of the usual (re)presentations of bodies, before opening the way to the construction of future selves, affirming other views of the subject, the stigma and the world. The open paradigm we have described here might as well be called open perspectives, both on the individual and the community level. 
Further research will need to be conducted on the perception of openness on all levels of the design process. To do so, we propose to meet the general public of an arts and science center with various probes, to gather insights on their relationships to bodies and imaginaries revolving around bodies and technologies. This will then lead to open ended workshops, on a long-term basis, which will allow for studying the perceptions of openness, and the reactions of the public to various prototypes

\section{Conclusion}

Through our study, we aimed to develop a framework allowing an analytical and critical discussion of design practices and projects claimed as open. Using this framework, we were able to reconsider the concept of openness from a broader perspective, and to assess a design's openness regarding to different aspects.

Our chosen examples demonstrated the diversity of ways a design initiative can claim openness, depending on context and intentions. We did not aim at evaluating their openness (as they all seem justified, in respect to their situation), but to use them in order to elaborate on the concept of openness and on its potential contribution to design.

It appears that openness might set an aesthetic paradigm in which design practice should consider its production as establishing encounters between agents (living and non-living) that reframe the existing world. Design practice in an open manner involves the reframing, the redistribution of the agency through the definition of new design spaces. It necessitates the designer to share her part in the act of design and a part of her responsibility. This paradigm requires from the designer a different approach to her practice and its ends. Users are not considered as a group sharing common traits, whatever the number of people included, but as a diversity of agents we cannot claim to fully understand - and we thus need to allow them to express their particularities. 


\section{References}

Atkinson, P. (2011). Orchestral manœuvres in design. In Open Design Now (pp. 27-34). Amsterdam. BIS Publishers.

Agamben, G., Kishik, D., \& Pedatella, S. (2009). What Is an Apparatus? and Other Essays. Stanford, Calif: Stanford University Press.

Aitamurto, T., Holland, D., \& Hussain, S. (2015). The Open Paradigm in Design Research. Design Issues, 31(4), 17-29. http://doi.org/10.1162/DESI_a_00348

Banerji, B., Banerji, J.B. (1984) A preliminary report on the use of cane and bamboo as basic construction materials for orthotic and prosthetic appliances. Prosthet Orthot Int. 8(2).

Barney, M. (n.d.). The CREMASTER. Retrieved March 11, 2016, from http://www.cremaster.net/

Bionico About. (n.d.). Retrieved from http://bionico.org/about/

Bowen, S. (2010). Critical theory and participatory design. In Proceedings of CHI. Citeseer. Retrieved from http://tinyurl.com/qha6743

BamBamProsthetics. (n.d.). Retrieved November 10, 2015, from http://www.bambamprosthetics.com/

Cruickshank, L. (2014) Open Design and Innovation: facilitating creativity in everyone. Ashgate Publishing.

Druin, A. (2002). The role of children in the design of new technology. Behaviour and Information Technology, 21(1), 1-25.

Eco, U. (1962). The Open Work. (A. Cancogni \& D. Robey, Trans. 1989). Cambridge, Mass: Harvard University Press.

Fishman, S., \& Kay, H. W. (1964). Acceptability of a Functional-Cosmetic Artificial Hand for Young Children, Part I. Artificial Limbs, 8(1). Retrieved from http://tinyurl.com/hrg5hl6

Gaver, W., Bowers, J., Boucher, A., Gellerson, H., Pennington, S., Schmidt, A., ... Walker, B. (2004, avril). The drift table: designing for ludic engagement. Retrieved from : http://www.chi2004.org/

Goëta, S. (2015). les coulisses de l'open data : sociologie de la production et de la libération de données publiques (unpublished doctoral dissertation).

Halskov, K., \& Hansen, N. B. (2015). The diversity of participatory design research practice at PDC 2002-2012. International Journal of Human-Computer Studies, 74, 81-92. http://doi.org/10.1016/j.ijhcs.2014.09.003 
Hurst, A., \& Tobias, J. (2011). Empowering Individuals with Do-it-yourself Assistive Technology. In The Proceedings of the 13th International ACM SIGACCESS Conference on Computers and Accessibility (pp. 11-18). New York, NY, USA: ACM. http://tinyurl.com/hgv493t

IKO Creative Prosthetic System - by Carlos Arturo Torres / Core77 Design Awards. (n.d.). Retrieved November 10, 2015, from http://tinyurl.com/h5jmazz

Kadushin, R. (2010). Open design manifesto. Ronan Kadushin Design. Retrieved from http://tinyurl.com/ospkl9j

Kensing, F., Blomberg, J., (1998). Participatory Design, Issues and Concerns. Computer Supported Cooperative Work 7: 167-185.

McClung Fleming, E. (1974). Artifact Study: a proposed model. Winterthur Portfolio, 9, 153-174.

Mivielle, C., \& Gentes, A. (2012). What is ludic about ludic design? Retrieved from http://tinyurl.com/gnrg4rs

O'Sullivan, S., \& others. (2010). From aesthetics to the abstract machine: Deleuze, Guattari and contemporary art practice. Deleuze and Contemporary Art, 189-207.

Open Knowledge. (2015). Open Knowledge: What is Open? Retrieved November 4, 2015, from https://okfn.org/opendata/

Pillet, J., \& Didierjean-Pillet, A. (2001). Aesthetic hand prosthesis: Gadget or therapy? Presentation of a new classification. The Journal of Hand Surgery, (28), 523-528.

Pine, J.B. (1993). Mass Customization : The New Frontier in Business Competition. Cambridge, Mass.: Harvard Business School Press.

Pullin, G. (2009). Design Meets Disability. MIT Press.

Redström, J. (2006). Towards user design ? On the shift from object to user as the subject of design. Design Studies, 27(2), 123-139. http://tinyurl.com/zmjbgcb

Salvador, F., de Holan, P. M., \& Piller, F. (2009). Cracking the Code of Mass Customization. In Sloan Management Revue.

Saner, E. (2014, December 20). Viktoria Modesta, the world's first amputee pop star: "If you don"t fit in, then don't fit in'. The Guardian. Retrieved from http://tinyurl.com/pstv5ks

Sansoni, S., Wodehouse, A., McFadyen, A., \& Buis, A. (2015). The Aesthetic Appeal of Prosthetic Limbs and the Uncanny Valley: The Role of Personal Characteristics in Attraction, 9(1), International Journal of Design. 
Thackara, J. (2011). Into the open. In Open design. BIS Publishers B.V.

Toupin, Sophie, 'Feminist Hackerspaces: The Synthesis of Feminist and Hacker Cultures', The Journal of Peer Production, 2014

Van der Beek, S. (2012). From representatino to rhizome : open design from a relational perspective. In the design journal 15(4), 423-442.

About the Authors:

Émeline Brulé is a designer and PhD student at Telecom-ParisTech. Her researches focus on the various implications of the current development of wearables. She has also been working on participatory design and DIY assistive technologies with visually impaired children.

Frédéric Valentin is a PhD student at TelecomParisTech. Through his research on the relations between design and openness he seeks to understand the particularities of an open work of design. He studied design at École Boulle and École Normale Supérieure de Cachan. 